\title{
TESTES DO CIRCUITO DE PREPARAÇÃO DE CARGA DO ALTO-FORNO 2 DA USINA DA VALLOUREC \& SUMITOMO TUBOS DO BRASIL (VSB)*
}

\author{
Aline Miranda Pessoa Passagli ${ }^{1}$ \\ Flávio Edmundo dos Anjos² \\ Juliene Karen Guedes ${ }^{3}$ \\ Onídio Teixeira Pinto Júnior ${ }^{4}$ \\ Paulo Afonso Ventura ${ }^{5}$ \\ Luís Cláudio de Abreu Germano 6
}

\section{Resumo}

No projeto da usina da Vallourec \& Sumitomo Tubos do Brasil (VSB), em Jeceaba MG está contemplado um circuito de preparação de carga para atender dois altosfornos de $350 \mathrm{~m}^{3}$ de volume útil. Realizaram-se algumas etapas de testes com carga que possibilitaram a verificação da capacidade real dos equipamentos e a eficiência de peneiramento das matérias-primas. Foram também realizados testes de simulação da amostragem e ensaios físicos das matérias-primas. Nesta contribuição técnica descrevem-se os testes realizados, avaliação dos mesmos e melhorias implantadas.

Palavras-chave: Matérias-primas; Alto-forno; Eficiência; Amostragem.

\section{TESTS OF BURDEN PREPARATION CIRCUIT OF VSB BLAST FURNACE 2}

\begin{abstract}
One circuit of burden preparation for two blast furnaces is considered in the project of VSB plant - Brazil. Some tests were carried out aiming to verify the actual capacity of the equipment and the raw materials screening efficiency. Other tests focusing on the raw materials sampling and the physical tests were also carried out. The tests, their results and evaluation are described in this paper.
\end{abstract}

Keywords: Raw materials; Blast furnace; Efficiency; Sampling.

1 Engenheira de Produção, coordenadora da equipe de controle de processo, gerência de altoforno, Vallourec \& Sumitomo Tubos do Brasil, Jeceaba, Minas Gerais, Brasil.

2 Engenheiro Metalurgista, coordenador da equipe de matérias-primas, gerência de alto-forno, Vallourec \& Sumitomo Tubos do Brasil, Jeceaba, Minas Gerais, Brasil.

3 Técnica em Mineração, técnica industrial, gerência de alto-forno, Vallourec \& Sumitomo Tubos do Brasil, Jeceaba, Minas Gerais, Brasil.

4 Engenheiro Metalurgista, gerente, gerência de alto-forno, Vallourec \& Sumitomo Tubos do Brasil, Jeceaba, Minas Gerais, Brasil.

5 Técnico em eletrônica industrial, supervisor de manutenção eletromecânica, gerência de manutenção da siderurgia, Vallourec \& Sumitomo Tubos do Brasil, Jeceaba, Minas Gerais, Brasil.

6 Engenheiro de Produção, coordenador técnico, gerência de controle de qualidade da siderurgia, Vallourec \& Sumitomo Tubos do Brasil, Jeceaba, Minas Gerais, Brasil.

* Contribuição técnica ao $44^{\circ}$ Seminário de Redução de Minério de Ferro e Matérias-primas, 15은 Simpósio Brasileiro de Minério de Ferro e 20 Simpósio Brasileiro de Aglomeração de Minério de Ferro, 15 a 18 de setembro de 2014, Belo Horizonte, MG, Brasil. 


\section{INTRODUÇÃO}

A usina da VSB está localizada no município de Jeceaba - MG e tem como produto final tubo de aço sem costura para o mercado de óleo e gás. A capacidade de produção de aço bruto da usina é de 1.000 .000 t por ano. As principais áreas da usina são:

- pelotização;

- alto-forno;

- aciaria;

- laminação;

- tratamento térmico;

- linhas acabadoras (fast casing, flex line e coupling shop).

O projeto da área de redução da usina contempla atender dois altos-fornos de 350 $\mathrm{m}^{3}$ de volume útil, estando já montado e pronto para início da operação o alto-forno 2. Embora projetado para uso de coque ou carvão vegetal, decidiu-se para o início de operação o uso de $100 \%$ de carvão vegetal.

O circuito de preparação de carga do alto-forno está ilustrado na figura 1.

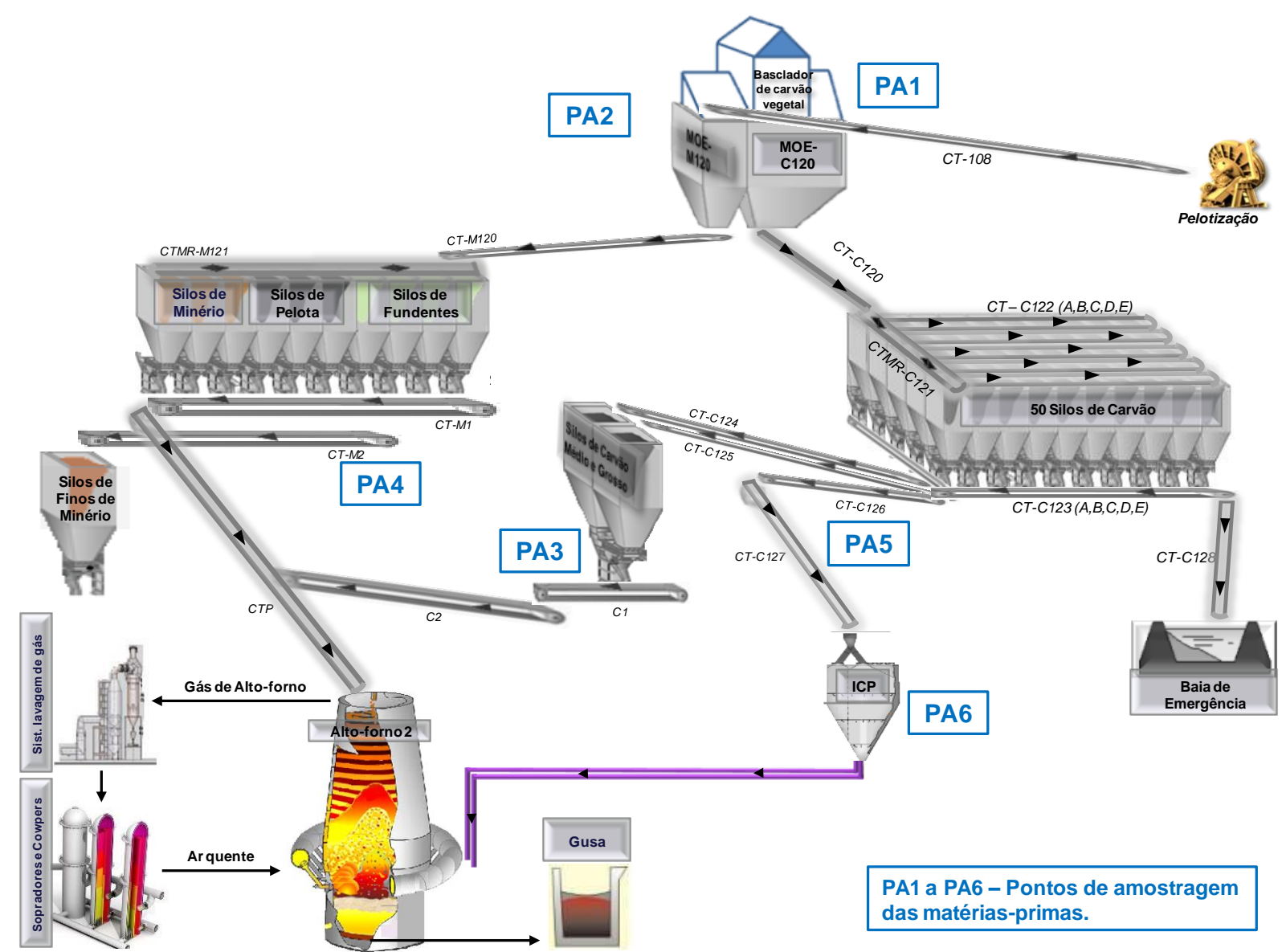

Figura 1. Fluxograma do circuito de preparação de carga e do alto-forno 2.

A Pelotização da VSB tem capacidade produtiva de 1.360 .000 toneladas por ano. Portanto, o abastecimento de pelotas para o alto-forno 2 é realizado via correia transportadora.

* Contribuição técnica ao 44 Seminário de Redução de Minério de Ferro e Matérias-primas, 15은 Simpósio Brasileiro de Minério de Ferro e $2^{\circ}$ Simpósio Brasileiro de Aglomeração de Minério de Ferro, 15 a 18 de setembro de 2014, Belo Horizonte, MG, Brasil. 
O minério de ferro granulado (minério) é fornecido pela Vallourec Mineração e é transportado por via rodoviária de forma a formar lotes no pátio de matérias-primas do alto-forno. Os fundentes são também estocados nesse pátio. $O$ abastecimento dos silos de minério, pelota e fundentes para consumo do alto-forno é realizado através da moega de metálicos e da correia transportadora de metálicos. Os silos de minério possuem sistema de secagem, que utilizam a fumaça gerada nos regeneradores. Abaixo dos silos de minérios há peneiras, para retirada dos finos do material.

A Vallourec Florestal é a responsável pelo fornecimento do carvão vegetal. $O$ transporte do carvão é por via rodoviária sendo que na recepção há um basculador com capacidade de 53 toneladas de carvão por hora. O abastecimento dos silos de carvão vegetal é realizado através da moega de redutores e da correia transportadora de redutores. São 50 silos de $220 \mathrm{~m}^{3} \mathrm{com}$ capacidade total de estocagem para $2.500 \mathrm{t}$ de carvão vegetal.

Os 50 silos estão distribuídos em 5 linhas, e embaixo de cada linha há uma correia transportadora que transporta o material até cada uma das 5 peneiras existentes. $O$ peneiramento separa o carvão bruto em carvão grosso (38,1 a $125 \mathrm{~mm})$, carvão médio $(9,52$ a 38,1 mm) e finos de carvão - moinha $(<9,52 \mathrm{~mm})$.

A moagem e injeção de carvão pulverizado foi projetada para atender os dois altosfornos e tem capacidade produtiva de 16,3 t por hora. O gás de alto-forno é utilizado no gerador de gás quente.

Todas as matérias-primas de recebimento e matérias-primas beneficiadas são caracterizadas através de amostragem e ensaios físicos e químicos. Os pontos de amostragens que estão representados na figura 1 são para as seguintes matériasprimas:

- PA1 - Carvão vegetal de recebimento e fundentes de recebimento

- PA2 - Minério de recebimento

- PA3 - Carvão vegetal grosso e médio

- PA4 - Minério de abastecimento dos silos de estocagem, pelota de abastecimento dos silos de estocagem e minério peneirado

- PA5 - Finos de carvão vegetal

- PA6 - Carvão pulverizado

A amostragem é realizada pela equipe operacional das matérias-primas do altoforno. Os ensaios físicos e as análises químicas são realizados pelos laboratórios da área de qualidade da siderurgia.

Esta contribuição técnica tem como objetivo apresentar os testes realizados na área de matérias-primas e laboratórios, que fazem parte da preparação para o início de operação do alto-forno 2.

\section{MATERIAIS E MÉTODOS}

\subsection{Circuito de Minério de Ferro Granulado}

Realizaram-se testes no circuito de minério com o objetivo de verificar a capacidade dos equipamentos e verificar a eficiência de peneiramento. Foi utilizada pelota segregada produzida no início de operação da pelotização (doravante, denominada "lote $\mathrm{x}$ "). Neste material estavam presentes grandes quantidades de finos como também contaminações de granulometria elevada (cascões).

Segue tabela $1 \mathrm{com}$ as informações dos equipamentos do circuito de metálicos.

* Contribuição técnica ao $44^{\circ}$ Seminário de Redução de Minério de Ferro e Matérias-primas, 15오 Simpósio Brasileiro de Minério de Ferro e 2ํ Simpósio Brasileiro de Aglomeração de Minério de Ferro, 15 a 18 de setembro de 2014, Belo Horizonte, MG, Brasil. 
Tabela 1. Equipamentos do circuito de metálicos do alto-forno

\begin{tabular}{l|c}
\multicolumn{1}{c|}{ DESCRIÇÃO } & CAPACIDADE \\
\hline Moega de fundentes e metálicos & $127 \mathrm{~m}^{3}$ \\
\hline Alimentador vibratório da moega & $450 \mathrm{t} / \mathrm{h}$ \\
\hline Correia transportadora abastecimento stockhouse & $450 \mathrm{t} / \mathrm{h}$ \\
\hline Balança integradora & $450 \mathrm{t} / \mathrm{h}$ \\
\hline Amostrador automático & - \\
\hline Correia transportadora móvel e reversível & $450 \mathrm{t} / \mathrm{h}$ \\
\hline Silos de estocagem e de secagem de minérios & $90 \mathrm{~m}^{3}$ \\
\hline Alimentadores vibratórios dos silos de estocagem & $25 \mathrm{~m}^{3 / \mathrm{h}}$ \\
\hline Peneiras vibratórias & $25 \mathrm{~m}^{3 / \mathrm{h}}$ \\
\hline Silos de pesagem & $25 \mathrm{~m}^{3 / \mathrm{h}}$ \\
\hline $\begin{array}{l}\text { Correia transportadora do stockhouse para a correia principal de } \\
\text { abastecimento do alto-forno }\end{array}$ & $130 \mathrm{~m}^{3 / \mathrm{h}}$ \\
\hline Correia transportadora de finos & $12 \mathrm{~m}^{3 / \mathrm{h}}$ \\
\hline
\end{tabular}

Os testes iniciaram no dia 20/05/13. O "lote x" foi transferido do pátio da pelotização para o pátio de matérias-primas do alto-forno e o abastecimento da moega de metálicos foi realizado com a pá carregadeira. Nesta etapa, os "cascões" ficaram retidos na grelha fixa presente na moega.

O material foi transferido para os silos de estocagem de minérios através da correia transportadora de abastecimento do stockhouse, apurando-se o peso registrado na balança integradora. Retiraram-se incrementos de amostra no amostrador automático localizado na transferência da correia transportadora de abastecimento do stockhouse para a correia transportadora móvel e reversível, a fim de caracterizar o material antes do peneiramento.

O início do peneiramento ocorreu no segundo dia de teste. Foram realizadas amostragens na saída das peneiras para cálculo de eficiência de peneiramento.

A correia transportadora do stockhouse para a correia principal de abastecimento do alto-forno foi acionada para o lado inverso, de forma a transferir o material peneirado para o local cuja pilha foi formada. Os finos gerados no peneiramento foram transportados para o silo de finos de minério via correia transportadora de finos.

Ao final do teste, foram apurados os pesos de todos os materiais (pelota peneirada, cachos retidos na moega de recebimento, finos de pelota e pó de pelota oriundo do sistema de desempoeiramento).

\subsection{Circuito de Carvão Vegetal}

Realizaram-se testes no circuito de carvão vegetal com o objetivo de verificar a eficiência de utilizando o carvão recebido e estocado em setembro de 2013. Segue tabela 2 com as informações dos equipamentos do circuito de carvão vegetal.

\footnotetext{
* Contribuição técnica ao $44^{\circ}$ Seminário de Redução de Minério de Ferro e Matérias-primas, 15ํ Simpósio Brasileiro de Minério de Ferro e $2^{\circ}$ Simpósio Brasileiro de Aglomeração de Minério de Ferro, 15 a 18 de setembro de 2014, Belo Horizonte, MG, Brasil.
} 
Tabela 2. Equipamentos do circuito de carvão vegetal do alto-forno

\begin{tabular}{l|c}
\hline \multicolumn{1}{c|}{ DESCRIÇÃO } & CAPACIDADE \\
\hline Basculador & $450 \mathrm{~m}^{3} / \mathrm{h}$ \\
\hline Moega do basculador & $246 \mathrm{~m}^{3}$ \\
\hline Alimentador vibratório da moega & $450 \mathrm{~m}^{3} / \mathrm{h}$ \\
\hline Grelha vibratória de separação de tiço & - \\
\hline Correia transportadora de abastecimento dos 50 silos & $450 \mathrm{~m}^{3} / \mathrm{h}$ \\
\hline Balança integradora & - \\
\hline Amostrador automático & - \\
\hline Correia transportadora móvel e reversível & $450 \mathrm{~m}^{3} / \mathrm{h}$ \\
\hline Correias transportadoras de abastecimentos dos silos (linhas A a E) & $450 \mathrm{~m}^{3} / \mathrm{h}$ \\
\hline Silos de estocagem (linhas A a E) & $220 \mathrm{~m}^{3}(\mathrm{u} t i l)$ \\
\hline Comportas de descarga dos silos de estocagem (linhas A a E) & $200 \mathrm{~m}^{3 / h}$ \\
\hline Correia transportadora de descarga dos silos (linhas A a E) & $200 \mathrm{~m}^{3} / \mathrm{h}$ \\
\hline Peneiras das linhas A a E & $200 \mathrm{~m}^{3} / \mathrm{h}$ \\
\hline Correias transportadoras de carvão peneirado grosso, médio e finos & $280 \mathrm{~m}^{3} / \mathrm{h}$ \\
\hline Amostradores automáticos de carvão peneirado & - \\
\hline Silo de estocagem de carvão peneirado (grosso e médio) & $130 \mathrm{~m}^{3}$ \\
\hline
\end{tabular}

Os testes iniciaram no dia 02/04/14. A amostragem do carvão vegetal bruto foi realizada ao final da correia de descarga dos silos, na queda do carvão para a peneira, utilizando a pá de amostragem. A amostragem de carvão peneirado e moinha foram realizadas nos amostradores automáticos existentes nas correias transportadoras de carvão peneirado grosso, médio e moinha.

Foram realizados três ciclos de peneiramento, duas vezes cada, simulando diferentes vazões de alimentação da peneira, conforme tabela 3.

Tabela 3. Ciclos de peneiramento

\begin{tabular}{c|c}
\hline $\begin{array}{c}\text { \% de abertura da comporta } \\
\text { dos 50 silos }\end{array}$ & $\begin{array}{c}\text { Vazão de alimentação da peneira } \\
(\mathrm{t} / \mathrm{h})\end{array}$ \\
\hline 33 & $\sim 19,1$ \\
\hline 66 & $\sim 26,7$ \\
\hline 100 & $\sim 45,8$ \\
\hline
\end{tabular}

Para todos os ciclos, o tempo de comporta aberta foi de 2 segundos e o tempo de comporta fechada foi de 10 segundos.

\subsection{Testes de Simulação da Amostragem e Ensaios Físicos das Matérias- Primas do Alto-forno}

Para simular os laboratórios físico e químico no atendimento ao funcionamento do Alto-forno 2, foi seguido o plano de amostragem de matérias-primas de recebimento e beneficiadas. A figura 2 e a tabela 4 apresentam o plano de amostragem, as datas e duração dos simulados, respectivamente.

\footnotetext{
* Contribuição técnica ao $44^{\circ}$ Seminário de Redução de Minério de Ferro e Matérias-primas, 15ํ Simpósio Brasileiro de Minério de Ferro e $2^{\circ}$ Simpósio Brasileiro de Aglomeração de Minério de Ferro, 15 a 18 de setembro de 2014, Belo Horizonte, MG, Brasil.
} 


\begin{tabular}{|c|c|c|c|c|c|c|c|c|c|c|c|c|}
\hline \multirow[b]{2}{*}{$\mathrm{N}^{\circ}$} & \multirow[b]{2}{*}{$\begin{array}{c}\text { TIPO DE } \\
\text { MATÉRIA } \\
\text { PRIMA }\end{array}$} & \multirow[b]{2}{*}{ MATERIAL } & \multirow[b]{2}{*}{$\begin{array}{l}\text { LOCAL DE } \\
\text { AMOSTRAGEM }\end{array}$} & \multirow[b]{2}{*}{ PERIODICIDADE } & \multirow[b]{2}{*}{$\stackrel{\mathrm{N}^{\circ}}{\text { AMOSTRAS / DIA }}$} & \multirow[b]{2}{*}{ PONTO DE COLETA } & \multirow[b]{2}{*}{$\begin{array}{l}\text { ANÁLISE DE } \\
\text { UMIDADE }\end{array}$} & \multirow[b]{2}{*}{$\begin{array}{c}\text { ANÁLISE } \\
\text { GRANULOMÉTRICA }\end{array}$} & \multirow[b]{2}{*}{$\begin{array}{l}\text { PREPARAÇÄO } \\
\text { PARA ANÁLISE } \\
\text { QUIMICA }\end{array}$} & \multirow[b]{2}{*}{$\begin{array}{l}\text { ANÁLISE } \\
\text { QUIMICA }\end{array}$} & \multicolumn{2}{|c|}{$\begin{array}{l}\text { TEMPO DE RESPOSTA DAS } \\
\text { ANÁLISES }\end{array}$} \\
\hline & & & & & & & & & & & $\begin{array}{c}\text { UMIDADE, } \\
\text { GRANULOMETRIA } \\
\text { E PREPARACCÄO } \\
\text { PARA QUIMICA }\end{array}$ & QUimica \\
\hline 1 & \multirow{6}{*}{ 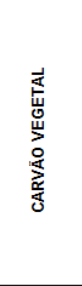 } & \begin{tabular}{c|c|c|c|c|} 
CV de \\
Recebimento
\end{tabular} & Na carreta & \begin{tabular}{|c|c|}
8 por turno \\
(a cada 1 hora)
\end{tabular} & 24 & $\begin{array}{l}\text { P1 - CV RECEBIMENTO E } \\
\text { FUNDENTES }\end{array}$ & 24 & - & - & - & 01 hora & - \\
\hline 2 & & $\begin{array}{c}\mathrm{CV} \text { de } \\
\text { Recebimento }\end{array}$ & $\begin{array}{l}\text { Na moega do } \\
\text { basculador }\end{array}$ & 3 por turno & 9 & $\begin{array}{l}\text { P1 - CV RECEBIMENTOE } \\
\text { FUNDENTES }\end{array}$ & 9 & 9 & 9 & 9 & 04 horas & 04 horas \\
\hline 3 & & \multirow{3}{*}{ CV Peneirado } & $\begin{array}{c}\text { AMOS CT-C124 } \\
\text { (grosso) }\end{array}$ & \begin{tabular}{|c|}
4 por turno \\
(a cada 2 horas)
\end{tabular} & 12 & $\begin{array}{l}\text { P3 - CV GROSSO E } \\
\text { MÉDIO }\end{array}$ & 12 & 6 & 6 & 6 & 01 hora & 04 horas \\
\hline 4 & & & $\begin{array}{c}\text { AMOS CT-C125 } \\
\text { (medio) }\end{array}$ & $\begin{array}{c}4 \text { por turno } \\
\text { (a cada } 2 \text { horas) }\end{array}$ & 12 & $\begin{array}{l}\text { P3 - CV GROSSO E } \\
\text { MÉDIO }\end{array}$ & 12 & 6 & 6 & 6 & 01 hora & 04 horas \\
\hline 5 & & & \begin{tabular}{|c|}
$\begin{array}{c}\text { AMOS CT-C126 } \\
\text { (moinha) }\end{array}$ \\
\end{tabular} & 1 por dia & 1 & P5 - MOINHA & 1 & $1 /$ semana & 1/semana & 1/semana & 24 horas & 24 horas \\
\hline 6 & & \begin{tabular}{|l|} 
CV Pulverizado \\
\end{tabular} & $\mathrm{PCl}$ & 1 por turno & 3 & P6 - PÓ DE INJEÇÃ̃O & 3 & 3 & 1 & 1 & 01 hora & 04 horas \\
\hline 7 & \multirow{4}{*}{$\begin{array}{l}\stackrel{0}{0} \\
\stackrel{0}{\frac{1}{4}} \\
\frac{\mathrm{w}}{2}\end{array}$} & $\begin{array}{c}\text { Minério de } \\
\text { recebimento }\end{array}$ & Pátio 942 & $\begin{array}{c}3 \text { por dia }(08: 00 \\
\text { às } 16: 00)\end{array}$ & 3 & $\begin{array}{l}\text { P2 - MINÉRIO DE FERRO } \\
\text { DE RECEBIMENTO }\end{array}$ & 3 & 3 & 3 & 3 & 18 horas & 18 horas \\
\hline 8 & & $\begin{array}{c}\text { Minério de } \\
\text { abstecimento } \\
\text { dos silos de } \\
\text { secagem }\end{array}$ & AMOS CT-M120 & 1 por dia & 1 & $\begin{array}{l}\text { P4 - MINÉRIO DE FERRO } \\
\text { E PELOTA }\end{array}$ & 1 & 1 & 1 & 1 & 18 horas & 18 horas \\
\hline 9 & & $\begin{array}{l}\text { Minério } \\
\text { Peneirado }\end{array}$ & \begin{tabular}{|c|}
$\begin{array}{c}\text { Saida da peneira } \\
\text { (Manual) }\end{array}$ \\
\end{tabular} & 1 por turno & 3 & $\begin{array}{l}\text { P4 - MINÉRIO DE FERRO } \\
\text { E PELOTA }\end{array}$ & 3 & 3 & 3 & 3 & 08 horas & 01 hora \\
\hline 10 & & $\begin{array}{l}\text { Pelota de } \\
\text { recebimento }\end{array}$ & $\begin{array}{c}\text { Pátio } 942 \text { (Pelotas) } \\
\text { ou CTMR-M121 }\end{array}$ & \multicolumn{7}{|c|}{$\begin{array}{l}\text { Somente nos momentos de formação do estoque no pátio do alto-forno ( } 1 \text { vez no mês) e em casos de parada da pelotização que } \\
\text { acarretará em abastecimento com pelota do estoque do pátio da pelotizaçẫo. }\end{array}$} & 24 horas & 06 horas \\
\hline 11 & \multirow{3}{*}{ 恚 } & Quartzo & Pátio 942 & 1 por semana & 0,14 & $\begin{array}{l}\text { P1 - CV RECEBIMENTOE } \\
\text { FUNDENTES }\end{array}$ & 1/semana & 1/semana & 1/semana & 1/semana & 24 horas & 06 horas \\
\hline 12 & & Dolomita & Pátio 942 & 1 por semana & 0,14 & $\begin{array}{l}\text { P1 - CV RECEBIMENTO E } \\
\text { FUNDENTES }\end{array}$ & $1 /$ semana & 1/semana & $1 /$ semana & 1/semana & 24 horas & 06 horas \\
\hline 13 & & $\begin{array}{l}\text { Minério de } \\
\text { Manganês }\end{array}$ & Pátio 942 & 1 por semana & 0,14 & $\begin{array}{l}\text { P1 - CV RECEBIMENTO E } \\
\text { FUNDENTES }\end{array}$ & 1/semana & 1/semana & 1/semana & 1/semana & 24 horas & 06 horas \\
\hline
\end{tabular}

Figura 2. Plano de amostragem das matérias-primas do alto-forno 2.

Tabela 4. Datas e duração dos simulados

\begin{tabular}{c|c|c}
\hline Número simulado & Data & Duração (horas) \\
\hline 1 & $18 / 12 / 13$ & 8 \\
\hline 2 & $17 / 01 / 14$ & 8 \\
\hline 3 & $29 / 01 / 14$ & 16 \\
\hline 4 & $13 / 02 / 14$ & 16 \\
\hline 5 & $27 / 02 / 14$ & 24 \\
\hline 6 & $07 / 03 / 14$ & 48 \\
\hline 7 & 13 e $14 / 03 / 14$ & 96 \\
\hline 8 & 25 a $28 / 03 / 14$ & 144 \\
\hline 9 & 23 a $28 / 04 / 14$ & \\
\hline
\end{tabular}

A figura 3 representa o fluxo do processo de amostragem das matérias-primas, coleta das amostras e realização dos ensaios físicos e químicos.

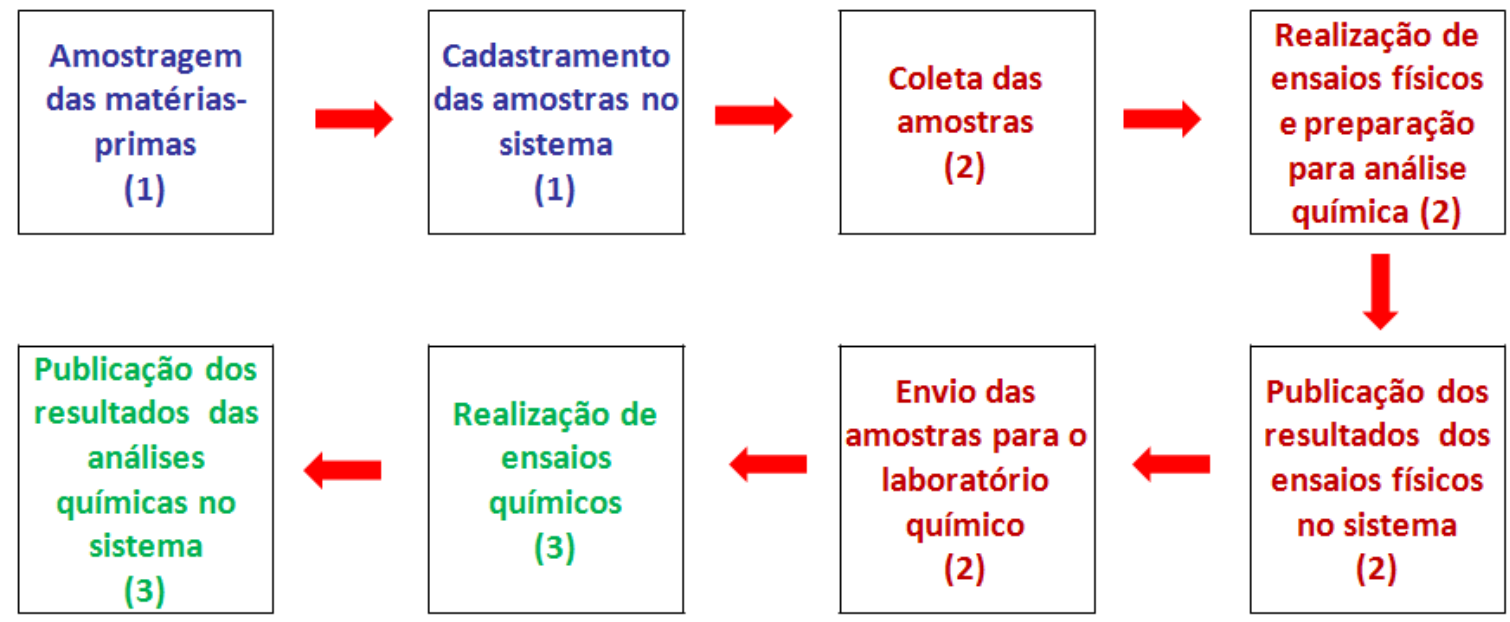

(1) Atividades da equipe de matérias-primas do alto-forno

(2) Atividades da equipe do laboratório físico

(3) Atividades da equipe do laboratório químico

Figura 3. Fluxo do processo amostragem das matérias-primas do alto-forno.

* Contribuição técnica ao 44 Seminário de Redução de Minério de Ferro e Matérias-primas, 15o Simpósio Brasileiro de Minério de Ferro e 2o Simpósio Brasileiro de Aglomeração de Minério de Ferro, 15 a 18 de setembro de 2014, Belo Horizonte, MG, Brasil. 


\section{RESULTADOS E DISCUSSÃO}

\subsection{Testes do Circuito de Minério de Ferro Granulado}

\subsubsection{Funcionamento dos equipamentos}

As figuras 4 a 7 apresentam os gráficos com os resultados de funcionamento de alguns dos equipamentos do circuito, no período entre 20/05/13 a 14/07/13. Os dados foram obtidos no PIMS (process information management system).

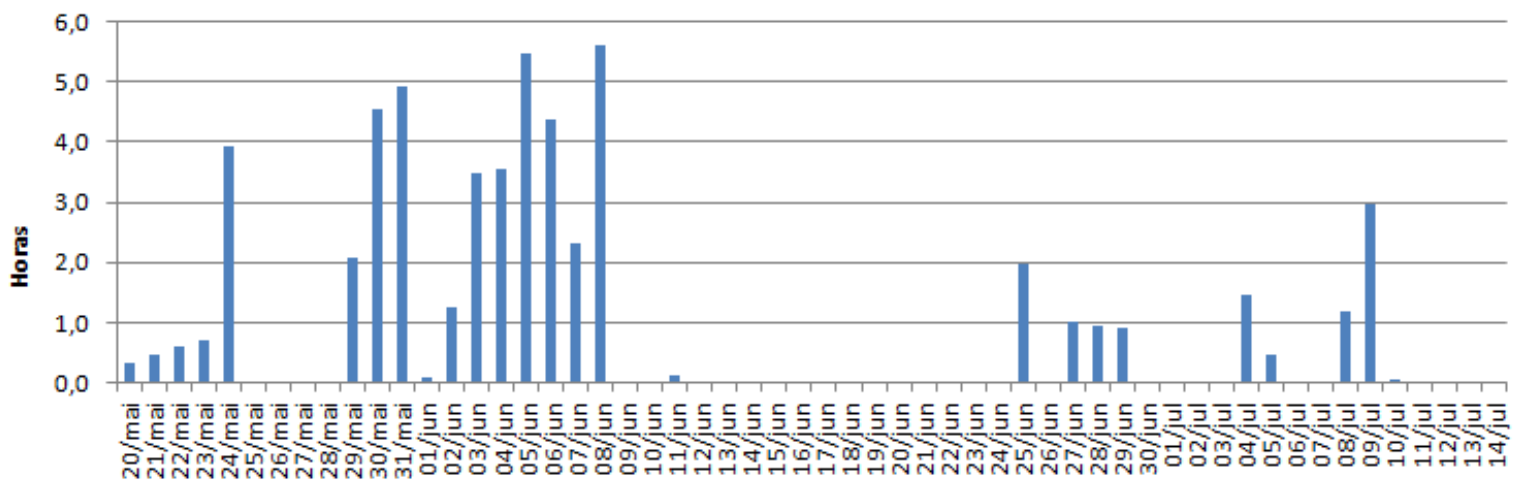

Figura 4. Funcionamento do alimentador vibratório da moega de metálicos.

Pode-se observar na figura 4 que entre os dias 12 e 25/06/13 não houve funcionamento do alimentador vibratório devido ao seu deslocamento ocorrido no dia 11. Durante este período os testes foram paralisados.

$\mathrm{Na}$ primeira semana o abastecimento da moega de recebimento e posterior transferência do material para o silo de minério ocorreu somente em um dos turnos, devido à disponibilidade de caminhão.

O tempo total de funcionamento do alimentador vibratório no período foi de 55 horas.

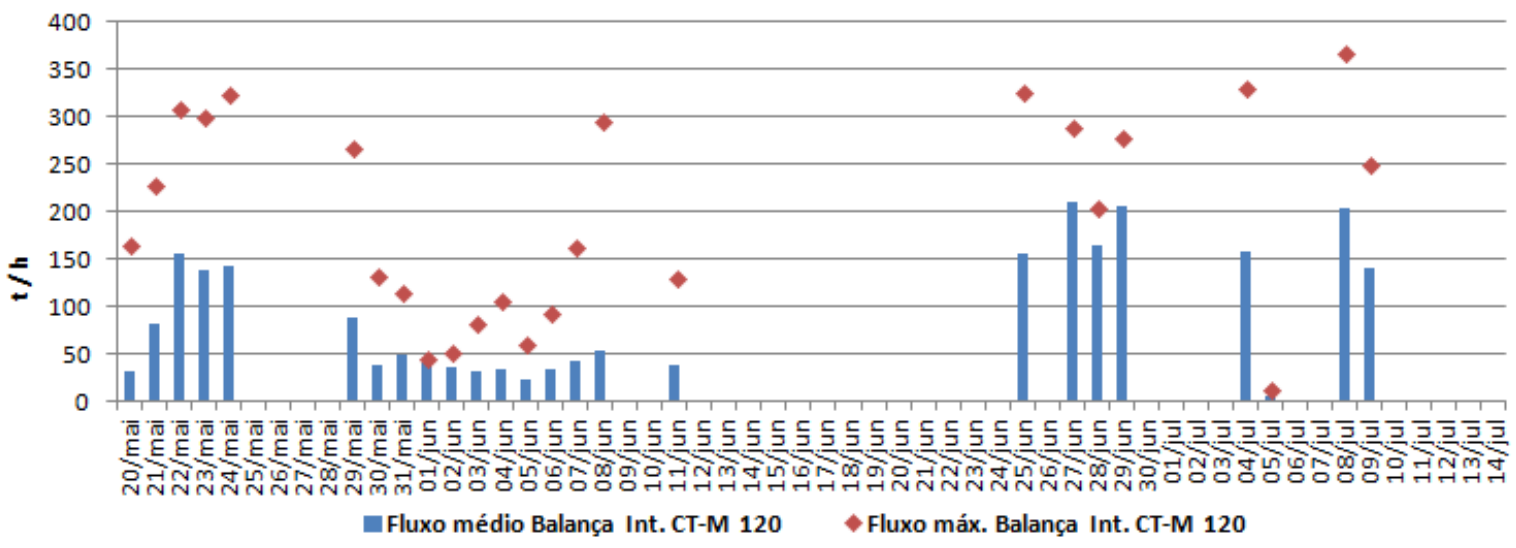

Figura 5. Fluxo da balança integradora da correia transportadora de abastecimento do stockhouse.

$\mathrm{Na}$ figura 5 pode-se observar pelas médias diárias de fluxo na balança integradora da correia transportadora de abastecimento do stockhouse que o alimentador vibratório e a correia transportadora não trabalharam em sua capacidade máxima, que é de $450 \mathrm{t} / \mathrm{h}$. Chegou-se a um fluxo máximo no dia 08/07 de $370 \mathrm{t} / \mathrm{h}$.

* Contribuição técnica ao 44ํ Seminário de Redução de Minério de Ferro e Matérias-primas, 15ํ Simpósio Brasileiro de Minério de Ferro e $2^{\circ}$ Simpósio Brasileiro de Aglomeração de Minério de Ferro, 15 a 18 de setembro de 2014, Belo Horizonte, MG, Brasil. 


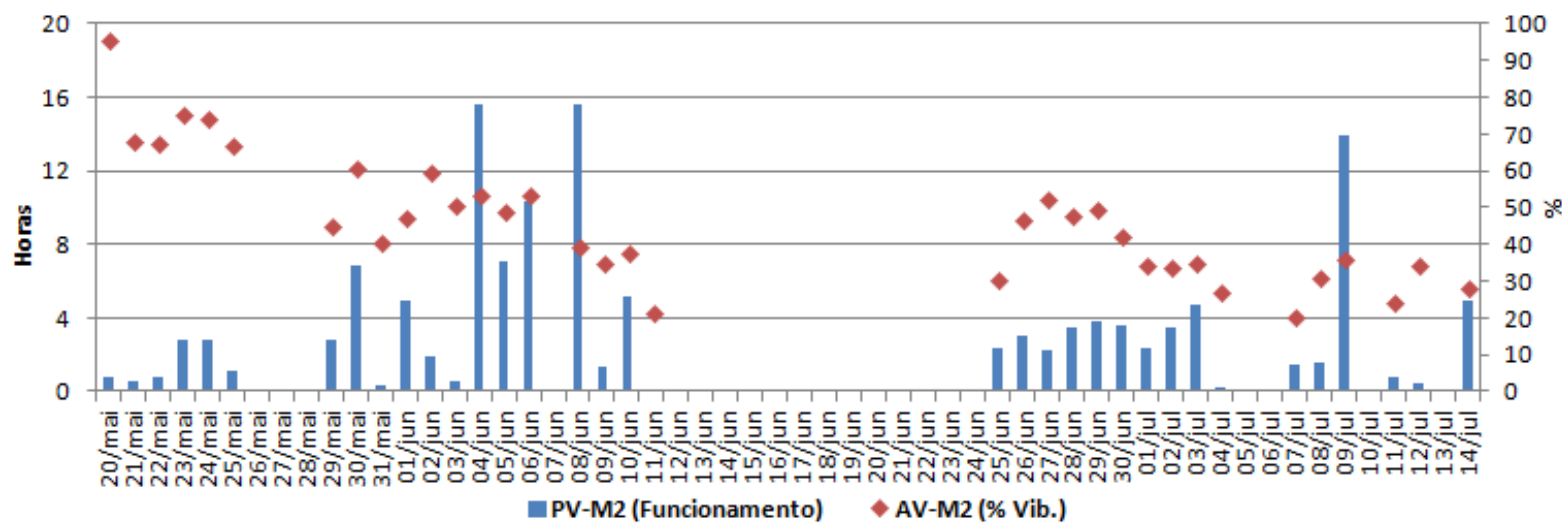

Figura 6. Funcionamento da peneira vibratória e \% de vibração do alimentador vibratório do silo de minério 02.

Observa-se na figura 6 que nos primeiros dias trabalhou-se com \% de vibração do alimentador vibratório da peneira elevado e depois adequou-se para valores abaixo de $60 \%$, a fim de obter uma altura de camada de pelota mais fina na peneira.

O tempo total de funcionamento do alimentador vibratório e da peneira vibratória do silo de minério 02 foi de 135 horas.

Após 3 semanas de testes, os silos de minério 01 e 03 também foram utilizados. Os tempos totais de funcionamento do alimentador vibratório e da peneira vibratória dos silos de minério 01 e 03 foram 82 e 64 horas, respectivamente.

O sistema de desempoeiramento funcionou por vários dias durante as 24 horas, conforme figura 7. As paradas foram realizadas em função de interrupções no peneiramento. O tempo total de funcionamento do sistema de desempoeiramento foi de 639 horas.

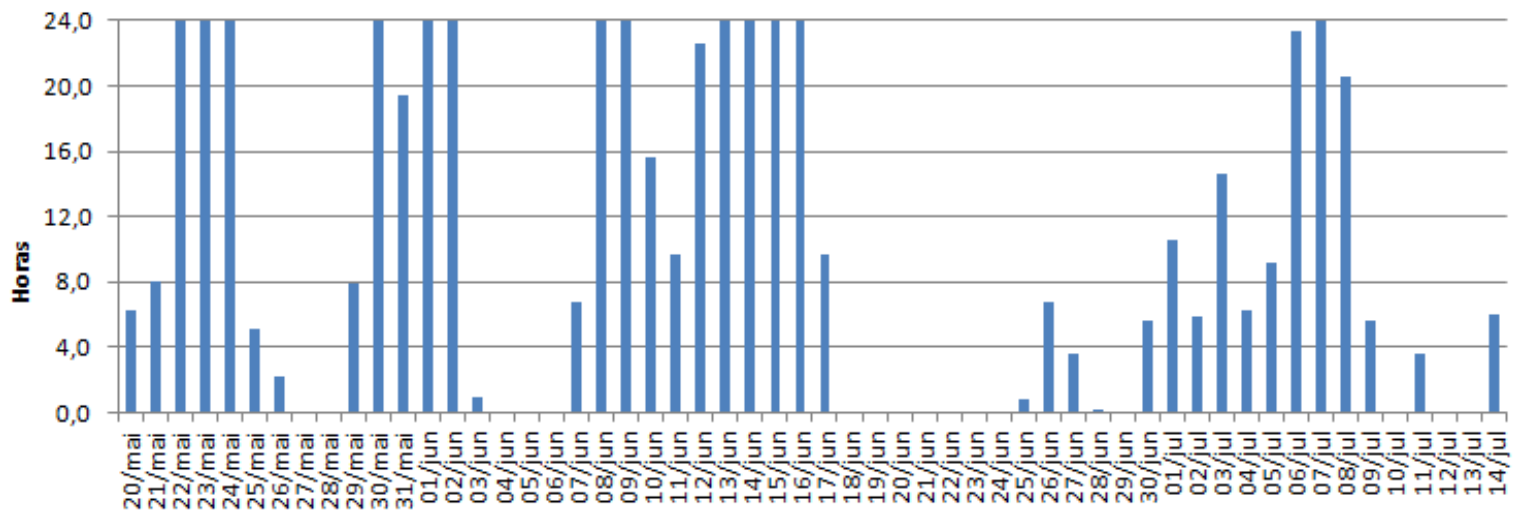

Figura 7. Funcionamento do sistema de desempoeiramento do stockhouse.

\subsubsection{Eficiência de peneiramento}

A eficiência de peneiramento é a qualidade de separação que a peneira fornece. Para peneiras industriais espera-se uma eficiência de peneiramento entre 90 e 96\%. $\mathrm{Na}$ literatura técnica [1], a equação 1 é a mais citada para cálculo de eficiência de peneiramento.

onde:

E: eficiência de peneiramento ( \%);

$P$ : quantidade de finos ( $t / h)$;

A: quantidade de alimentação $(\mathrm{t} / \mathrm{h})$;

a: fração fina na alimentação ( \% ).

* Contribuição técnica ao $44^{\circ}$ Seminário de Redução de Minério de Ferro e Matérias-primas, 15ํ Simpósio Brasileiro de Minério de Ferro e $2^{\circ}$ Simpósio Brasileiro de Aglomeração de Minério de Ferro, 15 a 18 de setembro de 2014, Belo Horizonte, MG, Brasil. 
Outra maneira de calcular a eficiência de peneiramento, representada na equação 2 , é utilizando os resultados da distribuição granulométrica do material que alimentou a peneira e do material retido [1].

onde:

$$
E=(1-(B / A)) \times 100
$$

E: eficiência de peneiramento ( \% );

A: \% de finos na alimentação;

B: \% de finos no material retido;

Esta eficiência é também chamada eficiência de recuperação dos passantes. Este é um cálculo prático e é muito usado nas áreas de redução das usinas siderúrgicas.

A figura 8 mostra os resultados das distribuições granulométricas médias realizadas nas amostras antes (total de 16 amostras) e após o peneiramento das pelotas (total de 45 amostras), com o cálculo de eficiência de peneiramento utilizando a equação 2 .

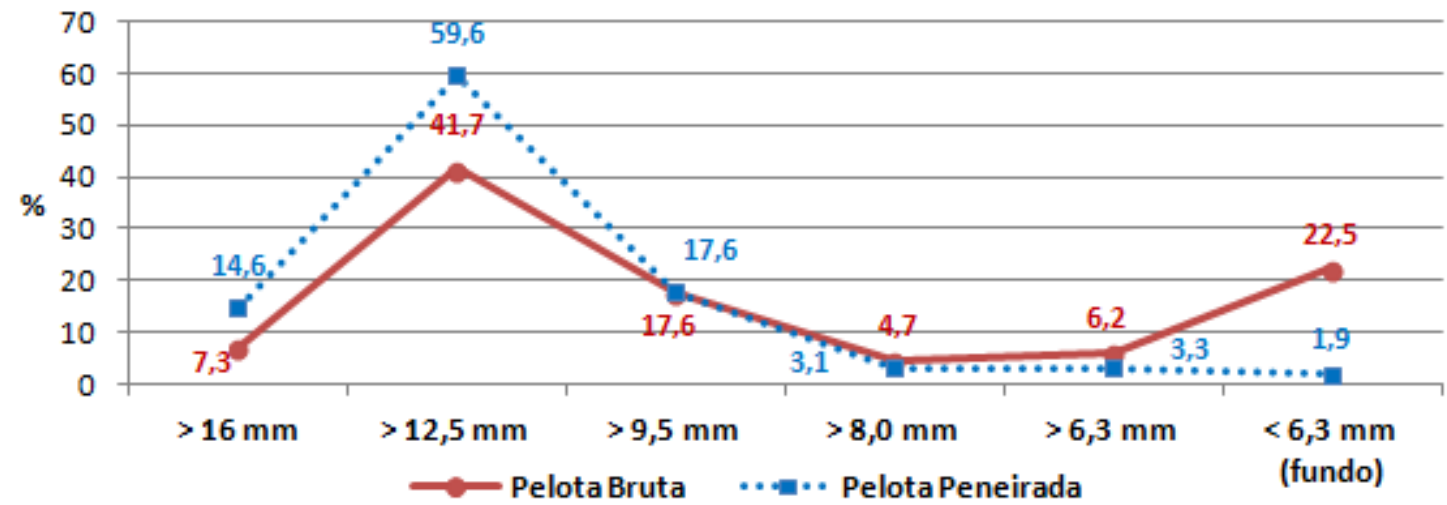

Figura 8. Distribuições granulométricas das pelotas - médias do período de teste.

O índice médio de eficiência de peneiramento obtido foi $91,5 \%$. Pode-se observar então que a eficiência de peneiramento do circuito de minério para as pelotas do "lote x" atendeu as expectativas, o que mostra uma boa performance das peneiras.

\subsubsection{Balanço de massa}

Os materiais obtidos após o peneiramento foram pesados de forma a fazer um balanço de massa (pelota depois do peneiramento, cachos retidos na moega de recebimento, finos de pelota e pó de pelota oriundo do sistema de desempoeiramento). A tabela 5 apresenta os resultados.

Tabela 5. Balanço de massa da pelota peneirada

\begin{tabular}{|c|c|c|c|}
\hline \multicolumn{2}{|l|}{ Entrada (t) } & \multicolumn{2}{|c|}{ Saída (t) } \\
\hline \multirow{4}{*}{$\begin{array}{l}\text { "Lote } x " \text { de pelotas recebidas no } \\
\text { pátio de matérias-primas do alto- } \\
\text { forno }\end{array}$} & \multirow{4}{*}{ 6.500} & Pelotas peneiradas & 5.879 \\
\hline & & Finos de pelotas & 523 \\
\hline & & Pó do desempoeiramento & 5 \\
\hline & & Cachos de pelotas & 56 \\
\hline
\end{tabular}

Comparando-se o balanço de massa com os ensaios de distribuição granulométrica, observa-se que a quantidade de finos de pelotas do "lote x" apurada (aproximadamente $8 \%$ ) é coerente com o resultado de eficiência de peneiramento obtido.

\footnotetext{
* Contribuição técnica ao 44 Seminário de Redução de Minério de Ferro e Matérias-primas, 15ํ Simpósio Brasileiro de Minério de Ferro e $2^{\circ}$ Simpósio Brasileiro de Aglomeração de Minério de Ferro, 15 a 18 de setembro de 2014, Belo Horizonte, MG, Brasil.
} 


\subsection{Testes do Circuito de Carvão Vegetal}

\subsubsection{Eficiência de Peneiramento}

As figuras 9 a 11 mostram as distribuições granulométricas do carvão bruto de recebimento, do carvão grosso (> 38,1 mm) e do carvão médio $(9,52$ a $38,1 \mathrm{~mm})$ das amostras obtidas nos três ciclos de peneiramento, simulando diferentes vazões de alimentação da peneira.

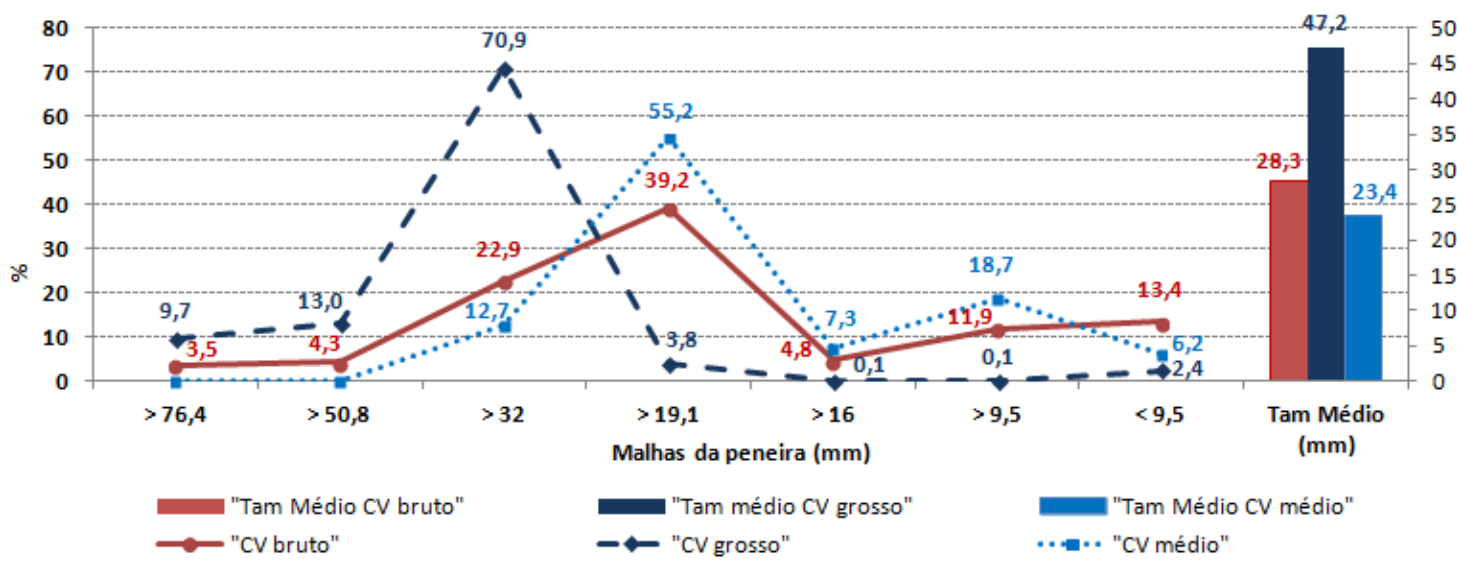

Figura 9. Distribuição granulométrica do carvão bruto x carvão grosso x carvão médio (abertura da comporta em 33\%).

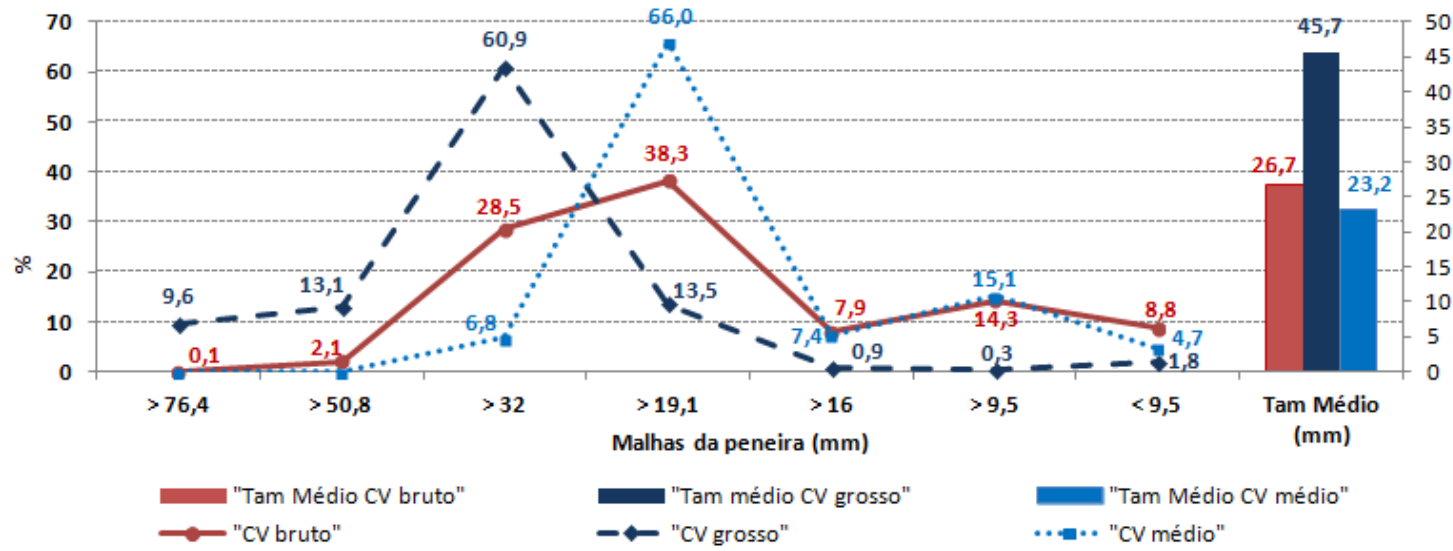

Figura 10. Distribuição granulométrica do carvão bruto $x$ carvão grosso x carvão médio (abertura da comporta em 66\%).

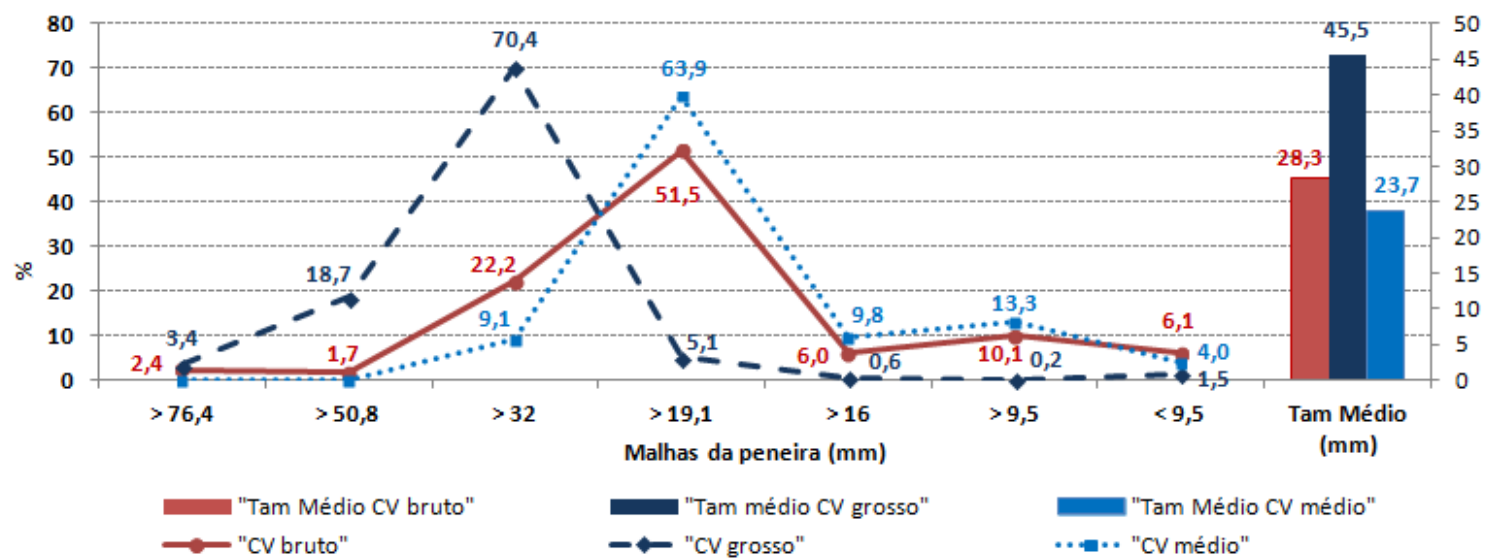

Figura 11. Distribuição granulométrica do carvão bruto $x$ carvão grosso x carvão médio (abertura da comporta em $100 \%)$.

* Contribuição técnica ao 44 Seminário de Redução de Minério de Ferro e Matérias-primas, 15은 Simpósio Brasileiro de Minério de Ferro e 20 Simpósio Brasileiro de Aglomeração de Minério de Ferro, 15 a 18 de setembro de 2014, Belo Horizonte, MG, Brasil. 
A figura 12 mostra o cálculo da eficiência de peneiramento do carvão grosso e do carvão médio nos três ciclos de peneiramento, utilizando a equação 2.

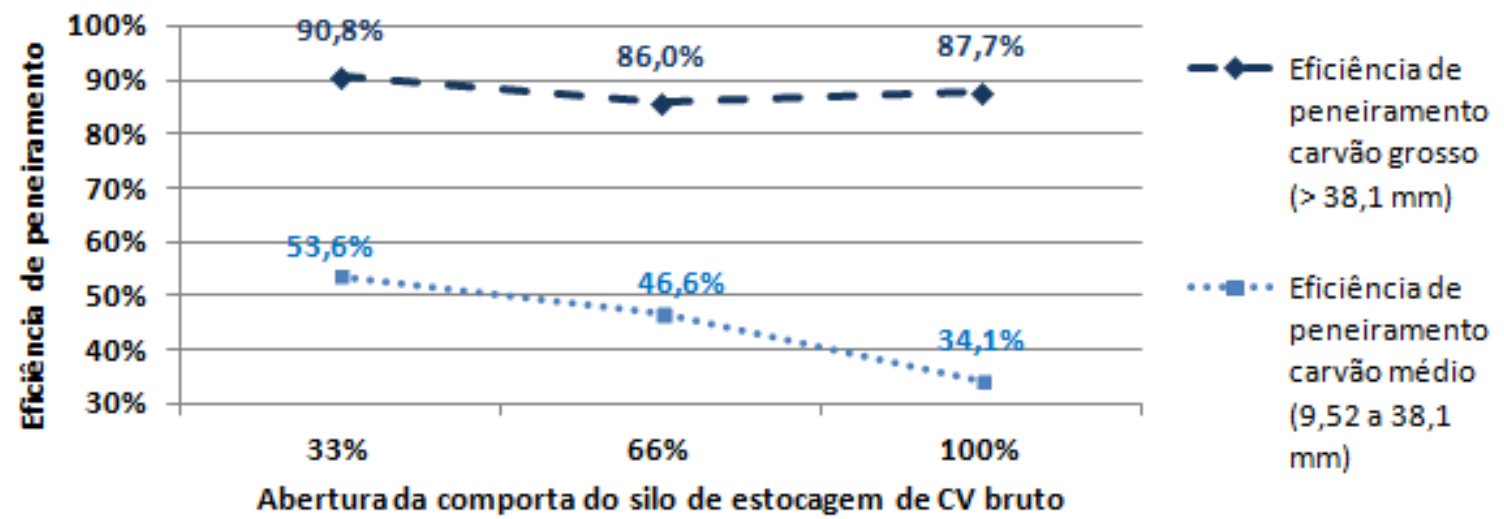

Figura 12. Eficiência de peneiramento do carvão vegetal grosso e do carvão médio.

Vale lembrar que o carvão bruto utilizado é um material já movimentado e peneirado diversas vezes, tendo influenciado nos resultados obtidos.

Os resultados da eficiência de peneiramento do carvão mostram que a eficiência de peneiramento do carvão grosso está melhor do que a eficiência de peneiramento do carvão médio. Estes resultados sinalizam a necessidade de realizar mais testes com vazões de alimentação menores e também ajustes nos equipamentos e procedimentos, como por exemplo, redução da abertura da tela superior da peneira de carvão, que separa o carvão grosso do carvão médio.

\subsection{Testes de Simulação da Amostragem e Ensaios Físicos das Matérias- Primas do Alto-Forno}

\subsubsection{Tempo de atendimento do laboratório físico}

O tempo de atendimento do laboratório físico é contabilizado a partir do horário de coleta das amostras nos pontos de amostragem até o horário de inclusão dos resultados dos ensaios físicos no sistema. Ao longo dos 9 simulados de amostragem e realização de ensaios físicos das matérias-primas do alto-forno, houve uma melhora significativa deste tempo de atendimento. Na figura 13 estão representados os tempos de atendimento do $9^{\circ}$ simulado, em que o laboratório físico apresentou seu melhor desempenho.

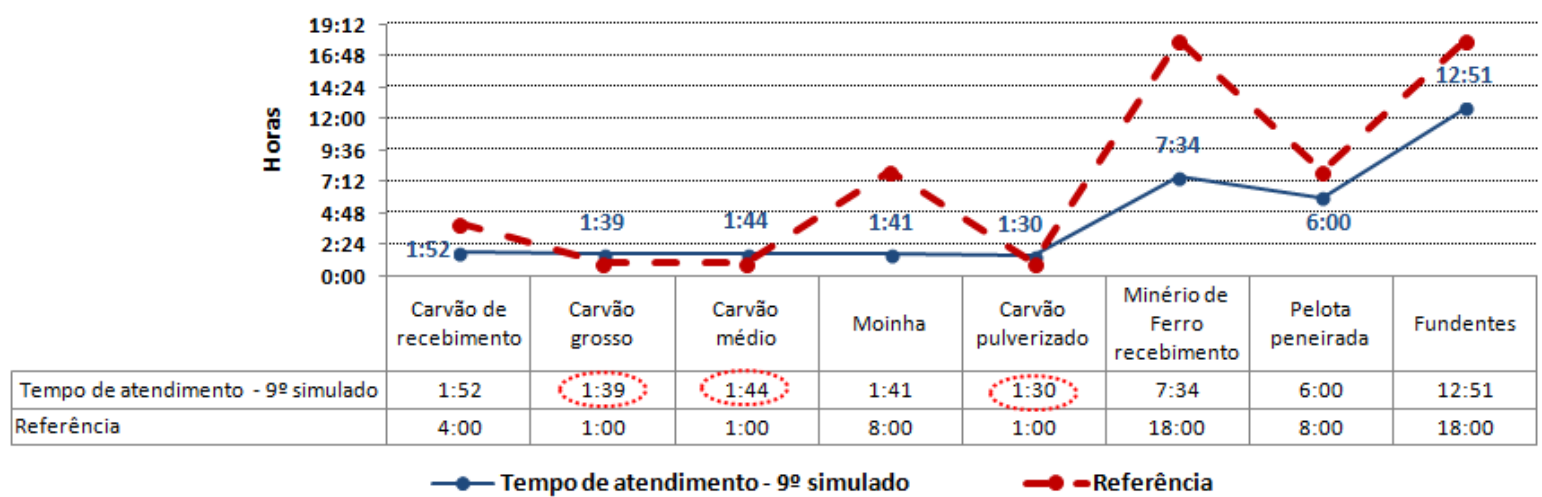

Figura 13. Tempo de atendimento do laboratório físico x valores de referência - 9ºsimulado.

\footnotetext{
* Contribuição técnica ao $44^{\circ}$ Seminário de Redução de Minério de Ferro e Matérias-primas, 15ํ Simpósio Brasileiro de Minério de Ferro e $2^{\circ}$ Simpósio Brasileiro de Aglomeração de Minério de Ferro, 15 a 18 de setembro de 2014, Belo Horizonte, MG, Brasil.
} 
Observa-se na figura 13 que os tempos de atendimento do laboratório físico para as amostras de carvão grosso, carvão médio e carvão pulverizado ainda não estão dentro dos valores de referência. Portanto, foi solicitada ao laboratório físico a aquisição da peneira horizontal para ensaio granulométrico do carvão vegetal, uma vez que sabe-se que com esta peneira o tempo de ensaio reduz significativamente, conforme experiência de outras empresas da siderurgia a carvão vegetal [2,3].

Para o carvão pulverizado, a ação foi priorizar seus ensaios em relação aos das outras matérias-primas, com exceção do carvão vegetal.

\subsubsection{Resultados de ensaios físicos}

No $1^{\circ}$ simulado ocorreu grande atraso na realização dos ensaios físicos e inclusão dos resultados no sistema, e alguns resultados foram incoerentes.

Os resultados de ensaios físicos do $2^{\circ}$ simulado em diante foram mais coerentes e satisfatórios, porém ainda ocorreram algumas não conformidades:

- perda de material no ensaio granulométrico;

- amostras publicadas no sistema faltando resultados de umidade ou de distribuição granulométrica;

- resultados de análise de umidade lançados incorretamente no sistema.

- ponto crítico: ensaios de carvão vegetal.

As figuras 14 e 15 mostram os resultados de tamanho médio das amostras de carvão médio e grosso, como também a evolução da perda de material no ensaio granulométrico ao longo dos 9 simulados.

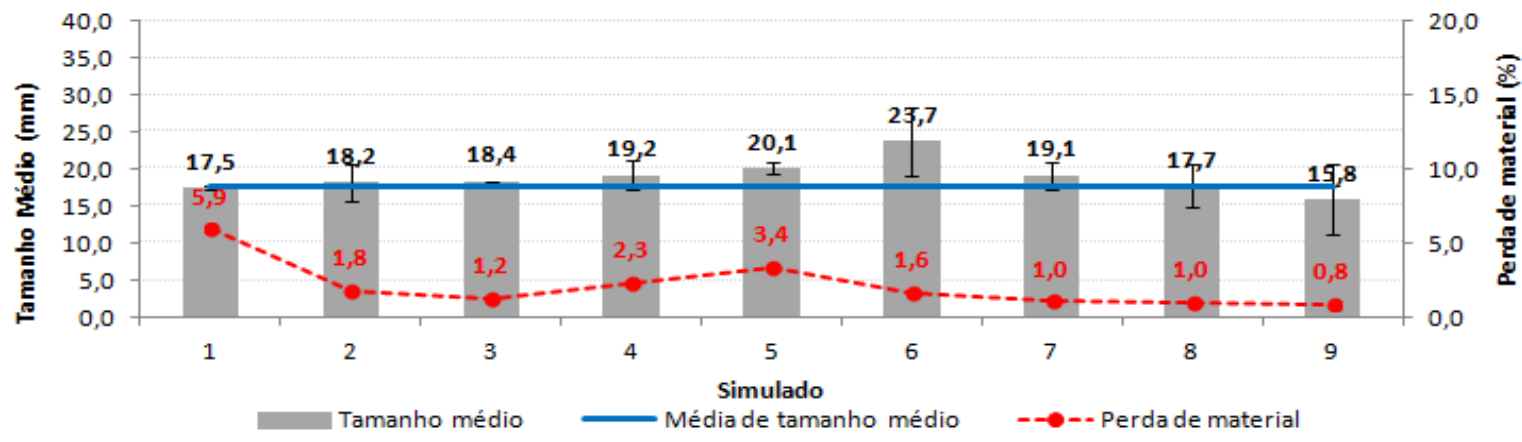

Figura 14. Resultados de tamanho médio e perda de material - carvão médio.

Observa-se que a perda de material no ensaio granulométrico do carvão médio ao longo dos 9 simulados diminuiu significativamente.

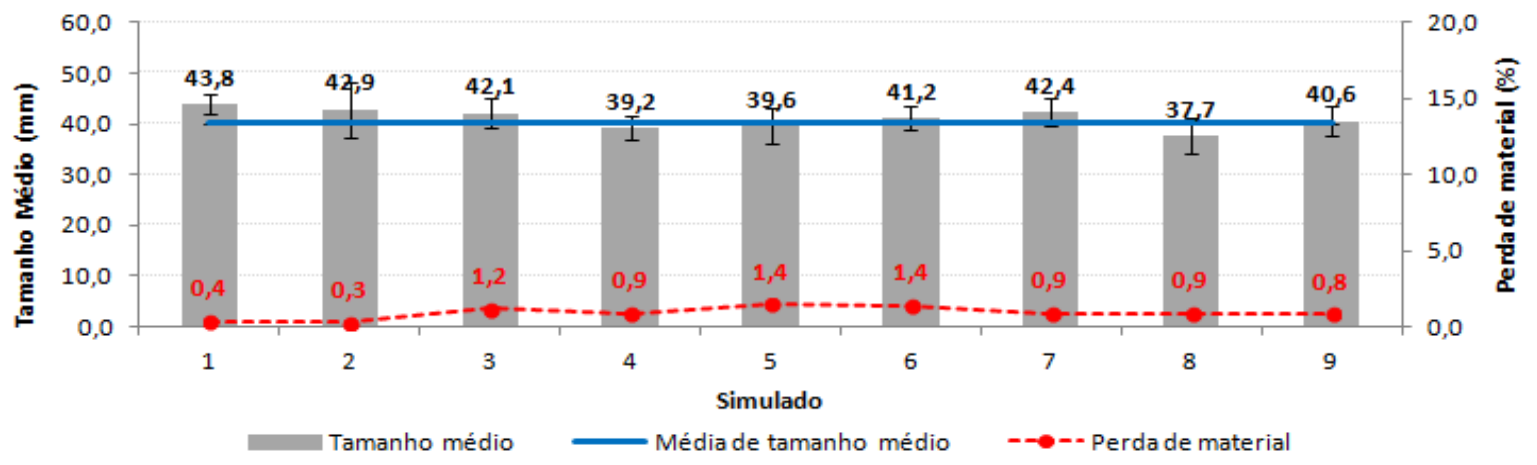

Figura 15. Resultados de tamanho médio e perda de material - carvão grosso.

* Contribuição técnica ao 44 Seminário de Redução de Minério de Ferro e Matérias-primas, 15은 Simpósio Brasileiro de Minério de Ferro e $2^{\circ}$ Simpósio Brasileiro de Aglomeração de Minério de Ferro, 15 a 18 de setembro de 2014, Belo Horizonte, MG, Brasil. 


\section{CONCLUSÃO}

As principais conclusões são:

- a partir dos testes no circuito de minério de ferro granulado e no circuito de carvão vegetal, foi possível treinar vários operadores novatos da equipe das matérias-primas, bem como verificar o funcionamento e capacidade dos equipamentos, o que gerou maior confiança para o início de operação do altoforno 2 da VSB;

- pode-se observar que a eficiência de peneiramento para pelotas do circuito de minério de ferro granulado atendeu as expectativas, o que mostra uma boa performance das peneiras;

- os resultados da eficiência de peneiramento do carvão mostram que a eficiência de peneiramento do carvão grosso está melhor do que a eficiência de peneiramento do carvão médio;

- estes resultados sinalizam a necessidade de realizar mais testes com vazões de alimentação menores e também ajustes nos equipamentos e procedimentos, como por exemplo, redução da abertura da tela superior da peneira de carvão, que separa o carvão grosso do carvão médio;

- ao longo dos 9 simulados de amostragem e realização de ensaios físicos das matérias-primas do alto-forno, houve uma melhora significativa do tempo de atendimento do laboratório físico.

\section{Agradecimentos}

Os autores agradecem as equipes de operação e de manutenção da área de preparação de carga do alto-forno da VSB e o professor Raimundo Braga, pelo apoio recebido.

\section{REFERÊNCIAS}

1 Chaves AP, Peres AEC. Britagem, peneiramento e moagem. 1999.

2 Guedes JK. Relatório técnico de visita a Vallourec Florestal. 2013.

3 Contatos pessoais com a Aperam. Fevereiro de 2014

* Contribuição técnica ao 44 Seminário de Redução de Minério de Ferro e Matérias-primas, 15오 Simpósio Brasileiro de Minério de Ferro e 2ํ Simpósio Brasileiro de Aglomeração de Minério de Ferro, 15 a 18 de setembro de 2014, Belo Horizonte, MG, Brasil. 